\title{
Editorial
}

\section{Genetic diagnosis of Alport syndrome}

\author{
Hae II Cheong, MD, PhD ${ }^{1,2}$ \\ ${ }^{1}$ Department of Pediatrics, Seoul National University Children's Hospital, Seoul, ${ }^{2}$ Kidney Research Institute, Medical Research Center, Seoul National University \\ College of Medicine, Seoul, Korea
}

In a recent issue of the Korean Journal of Pediatrics, Han et al." reported "de novo mutations in COL4A5 identified by whole exome sequencing in 2 girls with Alport syndrome.” Alport syndrome (AS), a prototype of hereditary glomerulonephritis, is clinically characterized by progressive renal failure with typical ultrastructural changes in the glomerular basement membrane (GBM), sensorineural hearing loss, and variable ocular abnormalities. ${ }^{2,3)} \mathrm{AS}$ is genetically heterogeneous and is caused by mutations in 1 of the 3 genes (COL4A3COL4A5) encoding the type IV collagen novel $\alpha$ chains, i.e., $\alpha 3-\alpha 5$ chains ( $\alpha 3[$ IV] $-\alpha 5[I V]){ }^{4)}$ Approximately 85\% of cases with AS have X-linked dominant inheritance (XL-AS) with COL4A5 mutations, and the remaining 15\% of cases have autosomal recessive (AR-AS) or rarely autosomal dominant (AD-AS) inheritance with mutations in either of the COL4A3 or COL4A4 genes. ${ }^{4}$

Like all other X-linked genetic disorders, the renal and extrarenal phenotypes of male patients with XL-AS are more severe than those of female patients. In contrast, the phenotypes of AR-AS are equally very severe in both male and female patients. Thus, the clinical diagnosis of AS may be difficult in some female patients or young boys with XL-AS who have isolated hematuria without hearing loss or ocular abnormalities. Furthermore, those patients may only have GBM thinning without any characteristic GBM changes. ${ }^{5}$ Although most female patients with XL-AS have a good renal outcome, approximately 15\% develop end-stage renal disease by the age of 60 years. Therefore, regular follow-up of female patients is required.

The clinical diagnosis of AS is highly likely under following conditions: (1) glomerular hematuria and a family history of AS with no other cause of hematuria, (2) typical extrarenal manifestations, such as bilateral high-tone sensorineural hearing loss, lenticonus, or fleck retinopathy, or (3) lack of $\alpha 3$ (IV)- $\alpha 5$ (IV) expression in the GBM by immunohistochemical analysis. ${ }^{3)}$ The diagnosis of AS is confirmed by the demonstration of lamellated GBM or a COL4A5 or biallelic COL4A3 or COL4A4 mutations. ${ }^{3)}$ The sensitivity and specificity of each of these diagnostic features for XL-AS are variable. Family history has high sensitivity and specificity; however, it may be absent in cases of patients with de novo mutations or patients with small family members. Approximately 15\% of patients with XL-AS have de novo COL4A5 mutations. ${ }^{6}$ Bilateral sensorineural hearing loss also occurs with aging, middle ear infections, and other inherited renal diseases. Although the incidences of lenticonus $(30 \%)$ and central fleck retinopathy (50\%) are not high, both are pathognomonic findings for AS. ${ }^{7}$ Lamellation of the GBM, a highly sensitive and specific finding, may be absent or focal in young boys and women but is progressive with time. ${ }^{5}$ Lack of $\alpha 3$ (IV)- $\alpha 5$ (IV) in the GBM is detected in $80 \%$ of male patients and $60 \%$ of female patients with mosaic pattern. ${ }^{3,8}$ The demonstration of a pathogenic COL4A5 variant confirms the diagnosis of XL-AS. The mutation detection rate in XL-AS is at least 90\% with a combinatorial approach of traditional Sanger sequencing, followed by multiplex ligation-dependent probe amplification to detect large deletions, insertions, or duplications. ${ }^{9)}$ Thus, whole exome sequencing is not routinely recommended for the genetic diagnosis of AS. In addition, it may be difficult to distinguish between pathogenic and nonpathogenic variants detected by whole exome sequencing.
Corresponding author: Hae II Cheong, MD, PhD Department of Pediatrics, Seoul National University Children's Hospital, 101 Daehak-ro, Jongno-gu, Seoul 03080, Korea

Tel: +82-2-2072-2810

Fax: +82-2-743-3455

E-mail: cheonghi@snu.ac.kr https://orcid.org/ 0000-0001-7556-1265

Received: 5 December, 2018 Revised: 27 December, 2018

Accepted: 31 December, 2018
Copyright (c) 2019 by The Korean Pediatric Society

This is an open-access article distributed under the terms of the Creative Commons Attribution NonCommercial License (http://creativecommons.org/ licenses/by-nc/4.0/ which permits unrestricted noncommercial use, distribution, and reproduction in any medium, provided the original work is properly cited. 
The genetic tests in AS allow accurate diagnosis as well as identification of the mode of inheritance, which is essential for genetic counseling for the family members. In addition, relative disease severity and prognosis can be predicted to some extent by genotypephenotype correlation. It is known that large deletions and rearrangements, nonsense mutations, and carboxy terminal missense mutations in COL4A5 typically result in early-onset renal failure, hearing loss, and ocular abnormalities, whereas amino terminal missense mutations in the gene are often associated with late-onset renal failure without the extrarenal features. ${ }^{10)}$ Genetic diagnosis is also useful in donor selection from family members. A relatively asymptomatic carrier woman who has donated one of her kidneys has an increased risk of hypertension, proteinuria, and renal failure in later life compared with other donors. Therefore, female carriers should only be kidney donors of last the resort.

In conclusion, clinical diagnosis is rather easy for male patients with XL-AS with typical renal and extrarenal manifestations as well as positive family history, and the diagnosis can be confirmed by detecting typical GBM changes in kidney biopsy specimens. However, in atypical cases, especially for women and young boys, clinical diagnosis may be difficult and genetic diagnosis is required. In addition, genetic diagnosis is essential for genetic counseling, donor selection, and so on. Because the mutation detection rate in $\mathrm{XL}$-AS with traditional sequencing is very high, whole exome sequencing is not routinely recommended. However, whole exome sequencing is advantageous in detecting large deletions, insertions, or duplications in female patients, which are normally not detected by traditional Sanger sequencing due to the presence of intact contralateral alleles.

\section{Conflicts of interest}

No potential conflict of interest relevant to this article was reported.

\section{References}

1. Han KH, Park JE, Ki CS. De novo mutations in COL4A5 identified by whole exome sequencing in two girls with Alport syndrome in Korea. Korean J Pediatr Forthcoming 2018.

2. Gubler M, Levy M, Broyer M, Naizot C, Gonzales G, Perrin D, et al. Alport's syndrome. A report of 58 cases and a review of the literature. Am J Med 1981;70:493-505.

3. Savige J, Gregory M, Gross O, Kashtan C, Ding J, Flinter F. Expert guidelines for the management of Alport syndrome and thin basement membrane nephropathy. J Am Soc Nephrol 2013;24:364-75.

4. Kruegel J, Rubel D, Gross O. Alport syndrome--insights from basic and clinical research. Nat Rev Nephrol 2013;9:170-8.

5. Savige J, Colville D, Rheault M, Gear S, Lennon R, Lagas S, et al. Alport syndrome in women and girls. Clin J Am Soc Nephrol 2016; 11:1713-20.

6. Jais JP, Knebelmann B, Giatras I, De Marchi M, Rizzoni G, Renieri A, et al. X-linked Alport syndrome: natural history and genotypephenotype correlations in girls and women belonging to 195 families: a "European Community Alport Syndrome Concerted Action" study. J Am Soc Nephrol 2003;14:2603-10.

7. Savige J, Sheth S, Leys A, Nicholson A, Mack HG, Colville D. Ocular features in Alport syndrome: pathogenesis and clinical significance. Clin J Am Soc Nephrol 2015;10:703-9.

8. Kashtan CE, Kleppel MM, Gubler MC. Immunohistologic findings in Alport syndrome. Contrib Nephrol 1996;117:142-53.

9. Hertz JM, Juncker I, Marcussen N. MLPA and cDNA analysis improves COL4A5 mutation detection in X-linked Alport syndrome. Clin Genet 2008;74:522-30.

10. Gross 0, Netzer KO, Lambrecht R, Seibold S, Weber M. Meta-analysis of genotype-phenotype correlation in X-linked Alport syndrome: impact on clinical counselling. Nephrol Dial Transplant 2002;17: 1218-27. 